\section{(6) OPEN ACCESS}

\title{
Association of synovial tissue polyfunctional T-cells with DAPSA in psoriatic arthritis
}

\author{
Sarah M Wade, ${ }^{1,2}$ Mary Canavan, ${ }^{1}$ Trudy McGarry, ${ }^{1,2}$ Candice Low, ${ }^{2}$ Siobhan C Wade, \\ Ronan H Mullan, ${ }^{3}$ Douglas I Veale, ${ }^{2}$ Ursula Fearon ${ }^{1}$
}

Handling editor Professor Josef S Smolen

- Additional material is published online only. To view please visit the journal online (http://dx.doi.org/10.1136/ annrheumdis-2018-214138).

${ }^{1}$ Molecular Rheumatology, School of Medicine, Trinity Biomedical Sciences Institute, Trinity College Dublin, Dublin 2 , Ireland

${ }^{2}$ St Vincent's University Hospital, Dublin Academic Health Care and University College Dublin, Dublin 4, Ireland

${ }^{3}$ Department of Rheumatology, Tallaght University Hospital, Dublin 24, Ireland

Correspondence to Professor Douglas J Veale, Molecular Rheumatology, School of Medicine, Trinity Biomedical Sciences Institute, Trinity College Dublin, Dublin D2 4, Ireland; douglas.veale@ucd.ie

Received 18 July 2018 Revised 29 November 2018 Accepted 18 December 2018 Published Online First 9 January 2019

\section{Check for updates}

(C) Author(s) (or their employer(s)) 2019. Re-use permitted under CC BY-NC. No commercial re-use. See rights and permissions. Published by BMJ.

To cite: Wade SM Canavan M, McGarry T, et al. Ann Rheum Dis 2019;78:350-354.

\section{ABSTRACT}

Objective This study examines polyfunctional T-cells in psoriatic arthritis (PSA) synovial tissue and their associations with clinical disease and implications for therapy.

Methods PsA synovial tissue was enzymatically/ mechanically digested to generate synovial tissue single cell suspensions. Frequencies of polyfunctional CD4, CD8, T-helper 1 (Th1), Th17 and exTh17 cells, using CD161 as a marker of Th17 plasticity, were determined by flow cytometry in matched PsA synovial tissue and peripheral blood. Synovial T-cell polyfunctionality was assessed in relation to Disease Activity in PSoriatic Arthritis (DAPSA) and in synovial cell suspensions cultured with a current mode of treatment, phosphodiesterase 4 (PDE4) inhibitor. Results PsA synovial tissue infiltrating $C D 4^{+}$-cells expressed higher levels of interleukin (IL)-17A, interferon gamma (IFN- $\gamma$ ), GM-CSF and CD161, with parallel enrichment of Th1, Th17 and exTh17 T-helper subsets (all $\mathrm{p}<0.05$ ). Interestingly, a significant proportion of synovial T-cell subsets were triple-positive for GMCSF, tumour necrosis factor (-TNF), -IL-17 or IFN- $\gamma$ compared with matched blood (all $p<0.05)$. Importantly, frequencies of polyfunctional T-cells correlated with DAPSA: Th1-GM-CSF ${ }^{+} / \mathrm{TNF}^{+} / \mathrm{IFN}-\gamma^{+}(r=0.7, p<0.01)$, Th17-GM-CSF $/ \mathrm{TNF}^{+} / \mathrm{IL}-17^{+}(\mathrm{r}=0.6, \mathrm{p}<0.057)$ and exTh17-GM-CSF ${ }^{+} / \mathrm{TNF}^{+} / \mathrm{IFN}-\gamma^{+}(\mathrm{r}=0.7, \mathrm{p}=0.0096)$, with no associations observed for single cytokine-producing T-cells. Following ex vivo culture of PsA synovial tissue cell suspensions, polyfunctional GM-CSF${ }^{+} T N F \alpha^{+} I L-17 A^{+}$ or/IFN- $\gamma^{+}$-producing T-cells $(p<0.05)$, but not single cytokine-producing T-cells, were inhibited with a PDE4 inhibitor.

Conclusion These data demonstrate enrichment of polyfunctional T-cells in PsA synovial tissue which were strongly associated with DAPSA and ex vivo therapeutic response.

\section{INTRODUCTION}

Psoriatic arthritis (PsA) is a chronic inflammatory arthropathy associated with psoriasis. Synovial inflammation is a pathological hallmark of PsA, characterised by dysfunctional angiogenesis, activation of synovial fibroblasts and infiltration of immune cells. ${ }^{12}$ Genetic and functional studies strongly support the role of T-cells in PsA pathogenesis. As a result, the targeted inhibition of dysfunctional T-cells in PsA has been an area of intensive investigation. Both CD4 and CD8 T-cells are found in abundance in the PsA synovium, ${ }^{23}$ with increased expression of the chemokine receptor C-C chemokine receptor type 4 (CCR4), a key component of

\section{Key messages}

What is already known about this subject?

- T-cells and their cytokines play a critical role in psoriatic arthritis (PsA) pathophysiology.

- Previous T-cell studies in PsA have focused on circulating and/or synovial fluid cells.

\section{What does this study add?}

- This is the first report of enrichment of a specific subset of novel polyfunctional T-cells in the synovial tissue from patients with PsA.

\section{How might this impact on clinical practice or} future developments?

- PsA synovial tissue polyfunctional T-cells significantly correlate with disease activity (Disease Activity in PSoriatic Arthritis) and response, thereby may guide treatment decisions and prognosis.

T-cell migration, also observed in synovial tissue and fluid. ${ }^{3}$ CD8 T-cells are clonally expanded in PsA synovium, ${ }^{45}$ while synovial enriched interleukin (IL) $-17^{+} \mathrm{CD} 8^{+} \mathrm{T}$-cells correlate with erosive disease. ${ }^{6}$ Within the CD4 T-cell compartment, several studies demonstrate elevated frequencies of circulatory T-helper 17 (Th17) cells in patients with PsA, with even higher numbers in the synovial fluid. ${ }^{6}$ Accumulating evidence suggests Th17 cells in PsA synovial fluid are associated with polyfunctional cytokine expression, ${ }^{7}$ where multiple cytokines including tumour necrosis factor alpha (TNF $\alpha$ ), granulocyte-macrophage colony-stimulating factor (GM-CSF and IL-22 are produced simultaneously and augment the complex local inflammatory environment. ${ }^{8}$ Indeed, T-cells have been recently targeted by modulation of T-cell costimulation, ${ }^{9}$ anti-IL-17 antibodies ${ }^{10}$ and blockade of the IL-23/ IL-12 axis, ${ }^{11}$ but with somewhat variable results. The effective targeting of T-cells requires a detailed characterisation of synovial T-cells and a full understanding of how these cells behave at the site of inflammation. However, as the T-cell profile of PsA synovial tissue has only been examined by immunohistochemistry or T-cell repertoire studies, little is known about the frequency of Th cell subsets, T-cell polyfunctionality and their relation to disease activity and therapy response.

In this study, for the first time, we demonstrate enrichment of synovial tissue polyfunctional CD4, CD8, Th1, Th17 and exTh17 cells compared with 
their circulatory counterparts. Furthermore, we show that it is these synovial tissue infiltrating polyfunctional T-cells, and not single cytokine-producing T-cells, that positively correlate with the clinical disease activity measure, Disease Activity in PSoriatic Arthritis (DAPSA), and response to therapy in ex vivo synovial cell cultures, suggesting these T-cell subsets play a key role in PsA pathogenesis.

\section{MATERIALS AND METHODS}

Online supplementary file 1.

\section{Enrichment of polyfunctional T-cells in PsA synovial tissue}

The frequency of synovial $\mathrm{CD}^{+}, \mathrm{CD}^{+}{ }^{+}, \mathrm{Th} 1, \mathrm{Th} 17$ and exTh17 cells and their ability to produce a combination of key T-cell-associated cytokines-interferon gamma (IFN- $\gamma$ ), GM-CSF, TNF $\alpha$ and IL-17A-was evaluated using multiparameter flow cytometry (gating strategy in online supplementary figure 1) on matched peripheral blood and synovial tissue from patients with PsA (online supplementary table 1). The frequency of CD4-derived IFN- $\gamma^{+}, \mathrm{IL}_{-}-17 \mathrm{~A}^{+}$and $\mathrm{GM}-\mathrm{CSF}^{+}$ was significantly increased in the synovial tissue of patients with PsA as compared with matched peripheral blood (all $\mathrm{p}<0.05$; figure $1 \mathrm{~A}$ ). In contrast, the frequency of CD4 $\mathrm{TNF}^{+}$ T-cells was significantly decreased in PsA synovial tissue $(p<0.05)$. Within the CD4 compartment, the levels of Th17 lineage marker, CD161, were significantly increased in PsA synovial tissue $(\mathrm{p}<0.05)$ (figure 1B). Using CD161 expression and cytokine expression, we demonstrated a significant increase in the frequency of Th1-CD161-IFN- $\gamma^{+}(\mathrm{p}<0.05)$, Th17-CD 161 ${ }^{+}$IL-17A $^{+}(\mathrm{p}<0.05)$ and exTh17-CD161 ${ }^{+}$IFN- $\gamma^{+}$ $(\mathrm{p}<0.05)$ in PsA synovial tissue compared with peripheral blood (figure 1B). No significant difference in the frequency of $\mathrm{GM}^{-\mathrm{CSF}^{+}}{ }^{+} \mathrm{TNF} \alpha^{+}, \mathrm{IL}^{-17 \mathrm{~A}^{+}}$and IFN- $\gamma^{+} \mathrm{CD} 8 \mathrm{~T}$-cells was observed in PsA synovial tissue (online supplementary figure 2).

Using Boolean gating strategy and SPICE software, we next explored the monofunctional and polyfunctional cytokine combinations produced by synovial resident and circulating T-cells in PsA, which demonstrated striking differences in synovial T-cells cytokine production compared with circulating
A
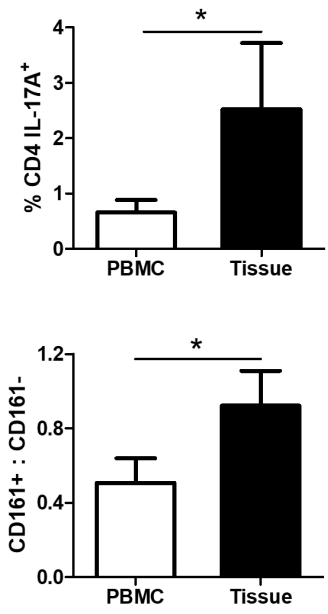

C

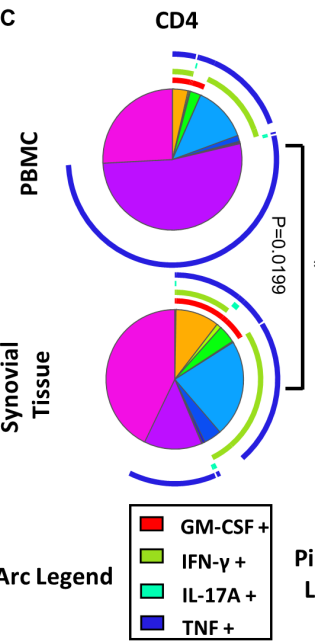

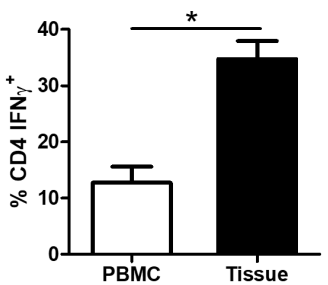

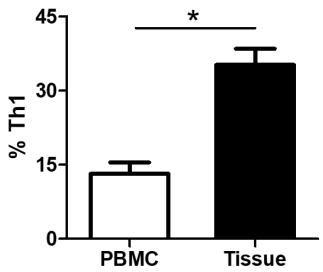

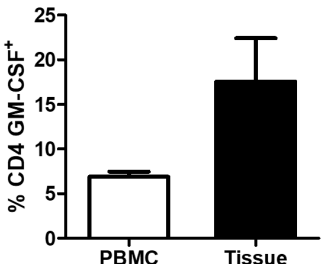

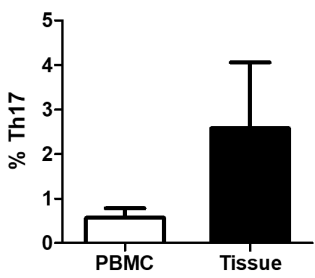

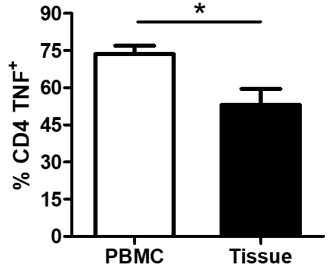

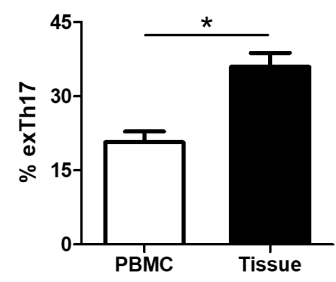

Figure 1 PsA synovial tissue infiltrating T-cells display cytokine polyfunctionality. (A) Frequency of CD4 T-cell-derived IL-17A, IFN- $\gamma$, GM-CSF and TNF $\alpha$ in the peripheral blood and synovial tissue of patients with PsA. (B) Frequency of CD161 ${ }^{+} / C D 161-$, Th1, Th17 and exTh17 cells in PsA peripheral blood and synovial tissue. (C) Heat-map coded pie charts demonstrating the cytokine profile of peripheral blood and synovial T-cells. Each section of the pie chart indicates different combinations of cytokine expression as denoted by the legend at the bottom of the graph. The pie chart arcs indicate the cytokine or cytokines produced by each proportion of cells. Polyfunctional cytokine data were analysed using the SPICE software. ${ }^{*} \mathrm{P}<0.05$,

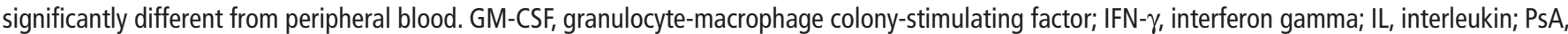
psoriatic arthritis; $T N F \alpha$, tumour necrosis factor alpha. 
T-cells (figure 1C). Single cytokine-positive cells are represented by individual arcs surrounding the pie charts, while double, triple and quadruple cytokine-positive T-cells were represented by overlapping arcs (figure 1C). A significant proportion of synovial T-cell subsets (CD4, CD8, Th1, Th17 and exTh17 cells) were triple-positive for $\mathrm{GM}-\mathrm{CSF}^{+} \mathrm{TNF}^{+} \mathrm{IL}_{-1}-17^{+}$or IFN- $\gamma^{+}$ compared with matched peripheral blood T-cells (all $\mathrm{p}<0.05)$. In particular, increased frequency of triple-positive synovial T-cells simultaneously secreting GM-CSF, TNF $\alpha$ and IL-17A (pie chart, orange segment) or GM-CSF, TNF $\alpha$ and IFN- $\gamma$ (pie chart, green segment) as compared with the peripheral blood was observed. The frequency of triple cytokine-positive T-cells was also increased in PsA synovial tissue compared with osteoarthritis (OA) synovium (online supplementary figure 3). Overall, a significant shift towards higher cytokine polyfunctionality in synovial tissue T-cells versus peripheral blood with paralleled decreases in frequency of single cytokine-producing T-cells was demonstrated ( $\mathrm{p}<0.05$; figure $1 \mathrm{C}$ ).

\section{Positive correlation between polyfunctional synovial tissue} Th1, Th17 and exTh17 cells with disease activity

The relationship between T-cell polyfunctionality and synovial inflammation was then examined in relation to disease activity by comparing the frequency of triple and single cytokine-positive synovial T-cells with DAPSA. ${ }^{12}$ Significant positive correlations were demonstrated between DAPSA and frequency of triple-positive infiltrating synovial T-cells
$\mathrm{GM}^{-\mathrm{CSF}^{+} \mathrm{TNF} \alpha} \alpha^{+} \mathrm{IFN}-\gamma^{+}(\mathrm{r}=0.70, \mathrm{p}<0.01), \mathrm{Th} 17-\mathrm{GM}^{-\mathrm{CSF}^{+}} /$ $\mathrm{TNF}^{+} / \mathrm{IL}_{-17^{+}} \quad(\mathrm{r}=0.6, \mathrm{p}<0.057)$ and exTh17-GM-CSF${ }^{+} /$ $\mathrm{TNF}^{+} / \mathrm{IFN}-\gamma^{+}(\mathrm{r}=0.7, \mathrm{p}=0.0096$; figure $2 \mathrm{~A})$. In contrast, single cytokine-producing synovial tissue Th1, Th17 and exTh17 cells did not positively correlate with any clinical measures of disease; indeed negative associations were observed (figure 2B). These data suggest that rather than their absolute frequencies, it is the polyfunctional cytokine capacity of synovial T-cells which is important in PsA disease pathogenesis.

\section{Effect of PDE4 blockade on polyfunctional synovial T-cells}

To examine if current therapies routinely used in the clinic affect synovial infiltrating T-cells' polyfunctionality, we next investigated in ex vivo PsA synovial tissue cell suspensions the effect of phosphodiesterase 4 (PDE4) inhibition on CD4, CD8, Th1, Th17 and exTh17 cytokine production. A significant reduction in cytokine polyfunctionality in rolipram-treated synovial suspensions was demonstrated $(p<0.05$, figure $3 \mathrm{~A}$; dose-dependent response in online supplementary figure 4 ). In particular, a significant reduction in the proportion of GM-CSF, TNF $\alpha$, IL-17A and/or IFN- $\gamma$ triple-positive (orange/ green segments) synovial CD4, CD8 ( $\mathrm{p}<0.05)$, Th1 ( $<<0.05)$, Th17 $(\mathrm{p}<0.05)$ and exTh17 $(\mathrm{p}<0.05)$ (figure $3 \mathrm{~B}$, upper right quadrants, and figure $3 \mathrm{C}$ ). Furthermore, these effects were not observed for single cytokine-producing T-cells, where the frequency of IFN- $\gamma$ only, Th1 and exTh17 cells (dark blue

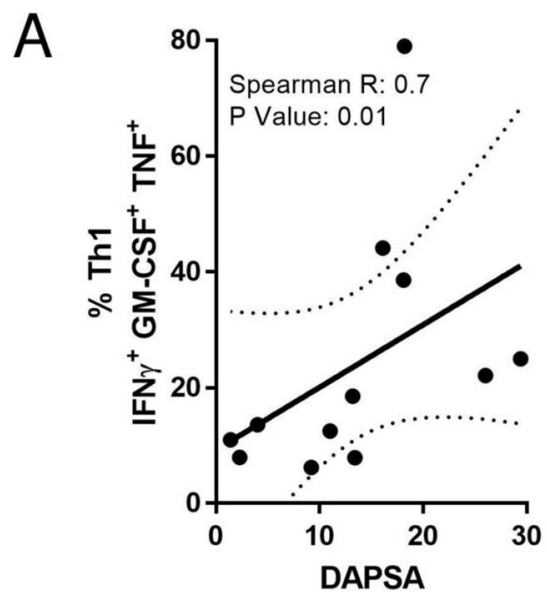

B

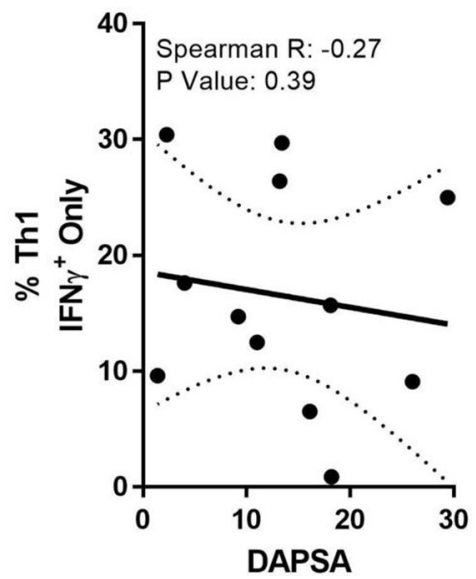

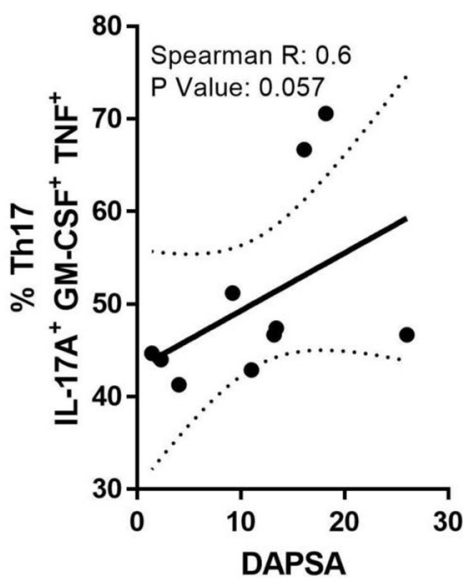

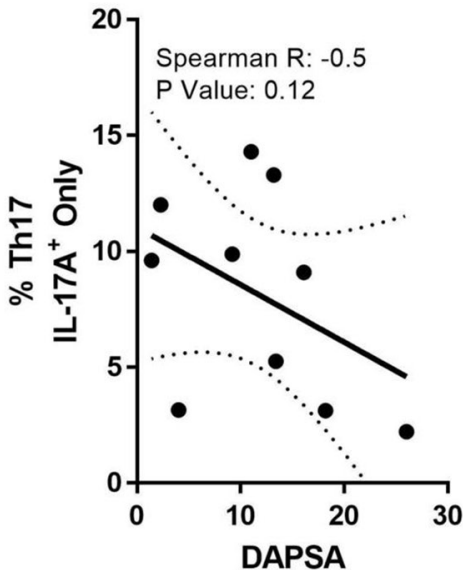

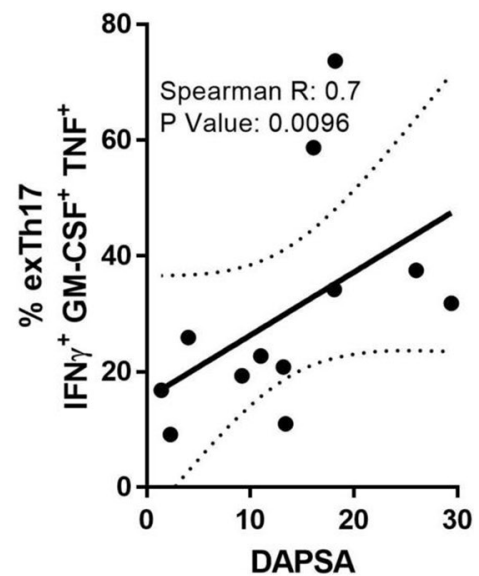

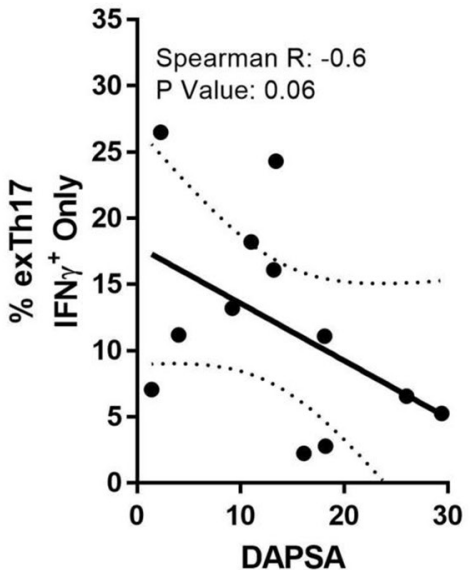

Figure 2 PsA synovial tissue T-cell polyfunctionality is positively associated with disease activity. The frequency of polyfunctional (A) triple cytokine and (B) single cytokine-positive Th1, Th17 and exTh17 plotted against disease activity score, DAPSA. Data are plotted with regression coefficients (solid line) and 95\% Cl (broken lines). DAPSA, Disease Activity in PSoriatic Arthritis; IL, interleukin; PsA, psoriatic arthritis; TNF, tumour necrosis factor. 
A

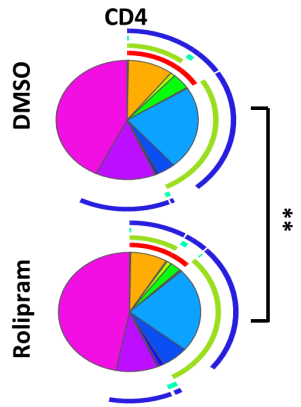

CD4 T-Cells
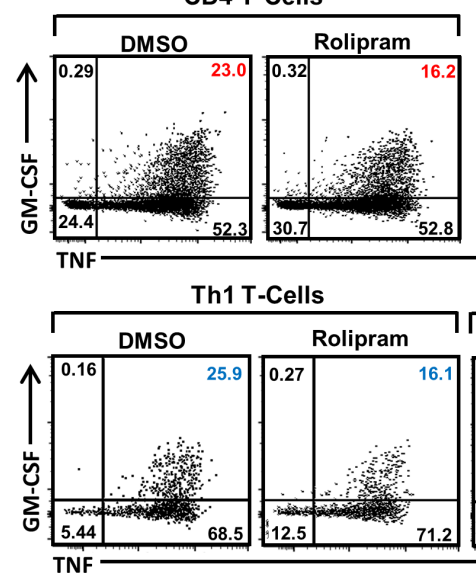

Th17 T-Cells

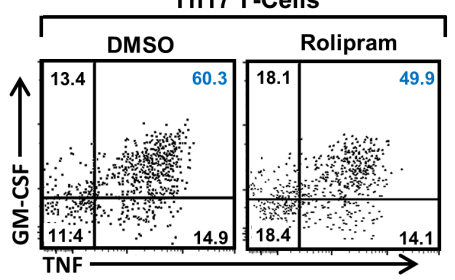

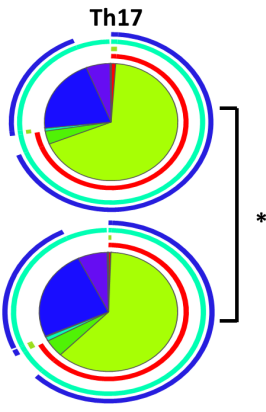

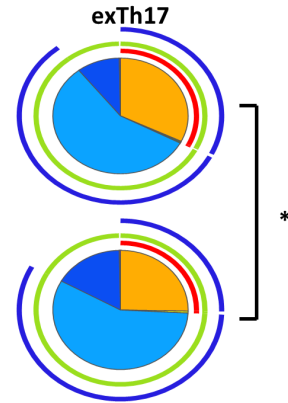

$c$
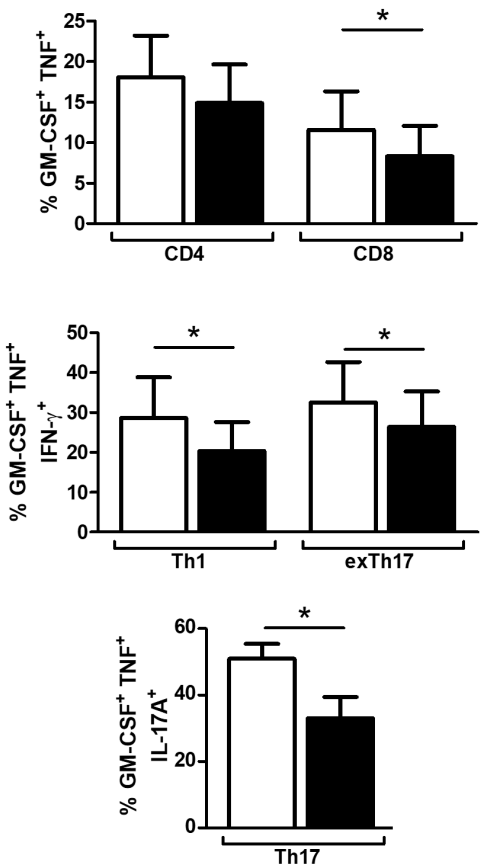

Figure 3 Phosphodiesterase 4 inhibition significantly reduces cytokine polyfunctionality of PsA synovial tissue T-cells. Cell suspensions were isolated from PsA synovial tissue and cultured in the presence of rolipram $(10 \mu \mathrm{M})$ or DMSO for 4 hours, stimulated with PMA and ionomycin in the presence of Brefeldin A for 4 hours and analysed by flow cytometry for intracellular expression of IL-17A, IFN- $\gamma$, TNF $\alpha$ and GM-CSF. (A) Pie charts representing the polyfunctional cytokine profile of CD4, CD8, Th1, Th17 and exTh17 synovial T-cells in the presence of rolipram (10 $\mu \mathrm{M})$ compared with DMSO control. Pie chart legend as per figure 2. The mean frequencies (B) and representative dot plots (C) of synovial tissue GM-CSF ${ }^{+} \mathrm{TNF}^{+} \mathrm{IL}-17 \mathrm{~A}^{+}$and/ or IFN- $\gamma^{+} \mathrm{CD} 4, \mathrm{CD} 8$, Th1, Th17 and exTh17 T-cells following 8-hour culture in the presence or absence of rolipram $(10 \mu \mathrm{M}) .{ }^{*} \mathrm{P}<0.05$, * ${ }^{*} \mathrm{p}<0.001$ significantly different from the DMSO control. DMSO, dimethyl sulfoxide; GM-CSF, granulocyte-macrophage colony-stimulating factor; IFN- $\gamma$, interferon gamma; IL, interleukin; PMA, phorbol myristate acetate; PsA, psoriatic arthritis; TNF $\alpha$, tumour necrosis factor alpha.

segment) was significantly increased in response to rolipram treatment (both $\mathrm{p}<0.05$; and online supplementary figure 5 ), with similar effects observed for IL-17A-only cells (dark purple segment and online supplementary figure 2).

\section{DISCUSSION}

This is the first study to examine T-cell polyfunctionality in single cell suspensions isolated from PsA synovial tissue and their association with measures of clinical disease activity. Flow cytometric analysis of synovial T-cells characterised a distinct T-cell signature that comprised enriched Th1, Th17 and exTh17 cells in PsA synovial tissue as compared with circulating T-cells, which were more polyfunctional in nature. Polyfunctional synovial tissue T-cells significantly correlated with PsA disease activity measures, in contrast to monofunctional T-cells, which negatively correlated with disease activity. Following ex vivo culture of PsA synovial tissue cell suspensions, polyfunctional GM-CSF ${ }^{+} \mathrm{TNF} \alpha^{+} \mathrm{IL}_{-17 \mathrm{~A}^{+}}$and/or IFN- $\gamma^{+}$-producing T-cells, and not single cytokine-producing
T-cells, were effectively inhibited by a PDE4 inhibitor, further suggesting that synovial tissue polyfunctional T-cells contribute to PsA pathogenesis.

In this study, we report for the first time elevated frequencies of Th1, Th17 and exTh17 cells in the synovium of patients with PsA. The Th17 lineage marker, CD161, was significantly elevated in PsA synovial tissue, suggesting a strong Th17 phenotype in PsA synovial pathology, which is consistent with previous findings. ${ }^{12-15}$ However, our data indicated that exTh17 and Th17 cells that have transitioned are also highly enriched in the PsA joint. While several studies have demonstrated Th17 plasticity in chronic inflammation, with elevated frequencies of exTh17 cells reported in psoriasis ${ }^{16}$ and rheumatoid arthritis synovial fluid, ${ }^{17}$ the mechanism for this remains unknown; however, IL-12 and IL-23, both implicated in PsA, have demonstrated the ability to promote Th17 plasticity in vitro. ${ }^{18}$ Despite being called non-classical Th1 cells, the joint specific Th17 lineage, exTh17 cells exhibit distinct pathogenic characteristics, including greater cytokine 
production, increased proliferation and resistance to Treg suppression. ${ }^{17}$ Our data now indicate that exTh17 cells are also likely to contribute to disease pathogenesis in PsA.

We also provide evidence that polyfunctional cytokine-expressing synovial T-cells may be key pathogenic mediators of PsA synovial inflammation. Synovial infiltrating T-cells exhibited greater cytokine polyfunctionality, particularly GM-CS$\mathrm{F}^{+} \mathrm{TNF}^{+} \mathrm{IFN}_{-} \boldsymbol{\gamma}^{+}$or IL-17A ${ }^{+}$positive T-cells, as compared with matched blood. Importantly, polyfunctional synovial T-cells, and not monofunctional single cytokine-producing T-cells, were positively associated with DAPSA, suggesting they are highly pathogenic in nature. This is consistent with previous studies showing augmented Th17 differentiation and polyfunctional cytokine expression with parallel skin hyperkeratosis, enthesitis and bone erosion in cutaneous and synovio-entheseal inflammation model of PsA. ${ }^{19}$ Interestingly, it has also been shown that antigen-specific T-cells exhibit cytokine polyfunctionality and enhanced immunity. ${ }^{20}$ This may be of particular interest for PsA as human leukocyte antigen (HLA)-27 polymorphism and infection are a recognised feature of PsA pathophysiology.

A PDE4 inhibitor reduced triple cytokine-positive GM-CS$\mathrm{F}^{+} \mathrm{TNF}^{+} \mathrm{IFN}-\gamma^{+}$and IL-17A ${ }^{+}$T-cells. Previous studies have demonstrated the targeted inhibition of T-cell-derived TNF $\alpha$, IFN- $\gamma$, IL-2, IL-4 and IL-17A in PsA peripheral blood in response to apremilast treatment ${ }^{21}$; however, the findings in this study now provide preliminary insights into potentially novel anti-inflammatory mechanisms in PsA synovial tissue. While the exact mechanism by which PDE4 blockade suppresses these polyfunctional T-cells is unclear, previous studies have demonstrated the importance of janus kinase/ signal transducer and activator of transcription (JAK/STAT) signalling in synovial T-cell differentiation, ${ }^{22}$ while the deletion of STAT5 in CD4 T-cells significantly impaired GM-CSF expression by CD4 T-cell. ${ }^{23}$

In conclusion, this is the first study to perform a detailed phenotypic analysis of synovial infiltrating T-cells in PsA. Synovial T-cells are polyfunctional in terms of cytokine expression, are positively associated with disease activity and are effectively repressed by PDE4 blockade. These data suggest that polyfunctional T-cells contribute to PsA pathogenesis.

Contributors SMW, MC, DJV, UF: developed the concept and wrote the paper. SMW, MC, TMG, SCW, CL, RHM, DJV, UF: generated and interpreted the data. UF, DJV: supervised the project. All authors critically reviewed and edited the paper.

Funding This study was sponsored by IRCSET and Arthritis Ireland.

Competing interests None declared.

Patient consent for publication Obtained.

Ethics approval Ethical approval to conduct this study was granted by St Vincent's Healthcare Group Medical Research and Ethics Committee and the Tallaght Hospital/ St James's Hospital Joint Research Ethics Committee. All experiments were performed in accordance with these guidelines and regulations.

Provenance and peer review Not commissioned; externally peer reviewed.

Data sharing statement All data from this study were published in the article or in the online supplementary information.

Open access This is an open access article distributed in accordance with the Creative Commons Attribution Non Commercial (CC BY-NC 4.0) license, which permits others to distribute, remix, adapt, build upon this work non-commercially, and license their derivative works on different terms, provided the original work is properly cited, appropriate credit is given, any changes made indicated, and the use is non-commercial. See: http://creativecommons.org/licenses/by-nc/4.0/.

\section{REFERENCES}

1 van Kuijk AW, Tak PP. Synovitis in psoriatic arthritis: immunohistochemistry, comparisons with rheumatoid arthritis, and effects of therapy. Curr Rheumatol Rep 2011:13:353-9.

2 Veale D, Rogers S, Fitzgerald O. Classification of clinical subsets en psoriatic arthritis classification of clinical subsets en psoriatic arthritis. Rheumatology 1994;33:133-8.

3 Flytlie HA, Hvid M, Lindgreen E, et al. Expression of MDC/CCL22 and its receptor CCR4 in rheumatoid arthritis, psoriatic arthritis and osteoarthritis. Cytokine 2010;49:24-9.

4 Costello PJ, Winchester RJ, Curran SA, et al. Psoriatic arthritis joint fluids are characterized by CD8 and CD4 T cell clonal expansions appear antigen driven. J Immunol 2001;166:2878-86.

5 Curran SA, FitzGerald OM, Costello PJ, et al. Nucleotide sequencing of psoriatic arthritis tissue before and during methotrexate administration reveals a complex inflammatory $T$ cell infiltrate with very few clones exhibiting features that suggest they drive the inflammatory process by recognizing autoantigens. J Immunol 2004; 172:1935-44.

6 Menon B, Gullick NJ, Walter GJ, et al. Interleukin-17+CD8+ T cells are enriched in the joints of patients with psoriatic arthritis and correlate with disease activity and joint damage progression. Arthritis Rheumatol 2014;66:1272-81.

7 Al-Mossawi MH, Chen L, Fang H, et al. Unique transcriptome signatures and GMCSF expression in lymphocytes from patients with spondyloarthritis. Nat Commun 2017:8:1510.

8 Kannanganat S, Ibegbu C, Chennareddi L, et al. Multiple-cytokine-producing antiviral CD4 T cells are functionally superior to single-cytokine-producing cells. J Virol 2007:81:8468-76.

9 Mease PJ, Gottlieb AB, van der Heijde D, et al. Efficacy and safety of abatacept, a T-cell modulator, in a randomised, double-blind, placebo-controlled, phase III study in psoriatic arthritis. Ann Rheum Dis 2017;76:1550-8.

10 Mclnnes IB, Mease PJ, Kirkham B, et al. Secukinumab, a human anti-interleukin-17A monoclonal antibody, in patients with psoriatic arthritis (FUTURE 2): a randomised, double-blind, placebo-controlled, phase 3 trial. The Lancet 2015;386:1137-46.

11 Paine A, Ritchlin CT. Targeting the interleukin-23/17 axis in axial spondyloarthritis Curr Opin Rheumatol 2016;28:359-67.

12 Fiocco U, Stramare R, Martini V, et al. Quantitative imaging by pixel-based contrastenhanced ultrasound reveals a linear relationship between synovial vascular perfusion and the recruitment of pathogenic IL-17A- $\mathrm{F}^{+} \mathrm{IL}-23^{+} \mathrm{CD} 161^{+} \mathrm{CD} 4^{+} \mathrm{T}$ helper cells in psoriatic arthritis joints. Clin Rheumatol 2017;36:391-9.

13 Baricza E, Marton N, Királyhidi P, et al. Distinct In Vitro T-Helper 17 differentiation capacity of peripheral naive t cells in rheumatoid and psoriatic arthritis. Front Immunol 2018:9:606.

14 Raychaudhuri SP, Raychaudhuri SK, Genovese MC. IL-17 receptor and its functional significance in psoriatic arthritis. Mol Cell Biochem 2012;359;-419-29.

15 Abji F, Pollock RA, Liang K, et al. Th17 gene expression in psoriatic arthritis synovial fluid and peripheral blood compared to osteoarthritis and cutaneous psoriasis. Clin Exp Rheumatol 2018;36:486-9.

16 Cosmi L, De Palma R, Santarlasci V, et al. Human interleukin 17-producing cells originate from a CD161+CD4+ T cell precursor. J Exp Med 2008;205:1903-16.

17 Basdeo SA, Cluxton D, Sulaimani J, et al. Ex-Th17 (Nonclassical Th1) cells are functionally distinct from classical Th1 and Th17 cells and are not constrained by regulatory T cells. J Immunol 2017;198:2249-59.

18 Bending D, De la Peña H, Veldhoen M, et al. Highly purified Th17 cells from BDC2.5NOD mice convert into Th1-like cells in NOD/SCID recipient mice. J Clin Invest 2009:119:565-72.

19 Yang L, Fanok MH, Mediero-Munoz A, et al. Augmented Th17 differentiation leads to cutaneous and synovio-entheseal inflammation in a novel model of psoriatic arthritis. Arthritis Rheumatol 2018:70:855-67.

20 Boyd A, Almeida JR, Darrah PA, et al. Pathogen-specific T cell polyfunctionality Is a Correlate of T cell efficacy and immune protection. PLoS One 2015;10:e0128714.

21 Schafer PH, Chen P, Fang L, et al. The pharmacodynamic impact of apremilast, an oral phosphodiesterase 4 inhibitor, on circulating levels of inflammatory biomarkers in patients with psoriatic arthritis: substudy results from a phase III, randomized, placebo-controlled trial (PALACE 1). J Immunol Res 2015;2015:1-10.

22 Fiocco U, Martini V, Accordi B, et al. Transcriptional network profile on synovial fluid T cells in psoriatic arthritis. Clin Rheumatol 2015:34:1571-80.

23 Sheng W, Yang F, Zhou Y, et al. STAT5 programs a distinct subset of GM-CSFproducing $T$ helper cells that is essential for autoimmune neuroinflammation. Cell Res 2014;24:1387-402. 